\title{
Design and Modeling of New UWB Metamaterial Planar Cavity Antennas with Shrinking of the Physical Size for Modern Transceivers
}

\author{
Mohammad Alibakhshi Kenari \\ Electrical Engineering Department of Shahid Bahonar, University of Kerman, Mazandaran-Fereydonkenar 4751677996, Iran \\ Correspondence should be addressed to Mohammad Alibakhshi Kenari; naeem.alibakhshi@yahoo.com
}

Received 7 February 2013; Revised 6 May 2013; Accepted 18 May 2013

Academic Editor: Francisco Falcone

Copyright (C) 2013 Mohammad Alibakhshi Kenari. This is an open access article distributed under the Creative Commons Attribution License, which permits unrestricted use, distribution, and reproduction in any medium, provided the original work is properly cited.

A variety of antennas have been engineered with MTMs and MTM-inspired constructs to improve their performance characteristics. This report describes the theory of MTMs and its utilization for antenna's techniques. The design and modeling of two MTM structures with $\varepsilon-\mu$ constitutive parameters for patch antennas are presented. The framework presents two novel ultrawideband (UWB) shrinking patch antennas filled with composite right-/left-handed transmission line (CRLH-TL) structures. The CRLH-TL is presented as a general TL possessing both left-handed (LH) and right-handed (RH) natures. The CRLHTL structures enhance left-handed (LH) characteristics which enable size reduction and large frequency bandwidth. The large frequency bandwidth and good radiation properties can be obtained by adjusting the dimensions of the patches and CRLH-TL structures. This contribution demonstrates the possibility of reducing the size of planar antennas by using LH-transmission lines. Two different types of radiators are investigated-a planar patch antenna composed of four $\mathbf{O}$-formed unit cells and a planar patch antenna composed of six $\mathbf{O}$-shaped unit cells. A CRLH-TL model is employed to design and compare these two approaches and their realization with a varying number of $L-C$ loaded unit cells. Two representative antenna configurations have been selected and subsequently optimized with full-wave electromagnetic analysis. Return loss and radiation pattern simulations of these antennas prove the developed concept.

\section{Introduction}

Nowadays miniaturized integrated antennas are becoming a relevant need in several application fields, such as communication systems, radio-sensors and RFID tags, radiating systems for automotive and radar applications, and emerging high-impedance nanoscale devices. While in the last decades, relevant efforts have been devoted towards achieving lowpower miniaturized electronic and RF components, miniaturized planar antennas of the same scale and with unchanged features are not readily available. For this reason, one of the main challenges in the front-end electronics of microelectronic components is the integration of miniaturized planar radiators in a printed chip, together with the remaining circuitry.
The multitude of potential techniques proposed over the years to squeeze the dimensions of planar antennas is mainly based on the reactive loading of a patch antenna with suitably designed slots, shorting posts, and lumped elements. These solutions, however, do not usually allow obtaining the drastic reduction of the antenna dimensions needed for the aforementioned applications $[1,2]$. Another possibility to squeeze the patch size is the employment of dielectric substrates exhibiting high values of the permittivity. However, due to the increased excitation of surface waves in the substrate, bandwidth, efficiency, and shape of the radiation pattern of the antenna may be significantly deteriorated [3].

The aforementioned standard techniques, therefore, do not represent sufficient tools to beat the challenge of miniaturized antenna design. Some new approaches, based on 


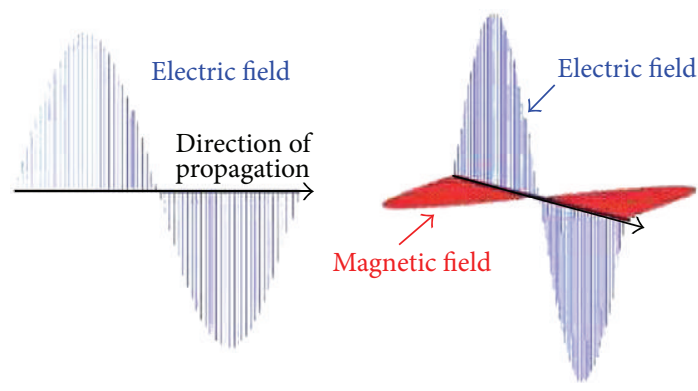

FIGURE 1: Electromagnetic waves.

the use of artificially engineered materials and metamaterials, seem to be more promising in this sense, opening the path to substantial achievements for the purposes of size reduction.

Metamaterial exhibits negative electrical permittivity and/or negative permeability [4,5]. These two properties determine how a material will interact with electromagnetic radiation including microwave, radio wave, $\mathrm{X}$-rays, and all other electromagnetic wavelengths. When both permittivity and permeability are simultaneously negative, its then having a negative refractive index or left-handed material. This relationship is shown by the following Maxwell equation for refractive index:

$$
n= \pm \sqrt{\varepsilon \mu}
$$

Electromagnetic waves are governed by Maxwell's equations, which show that these waves contain both electric and magnetic fields as shown in Figure 1. Electromagnetic waves consist of in-phase, oscillating electric and magnetic fields. Plane waves, as shown here, have electric and magnetic fields that are polarized at right angles to each other. The field directions in a plane wave also form right angles with respect to their direction of travel (the propagation direction). When an electromagnetic wave enters in a material, the fields of the wave interact with the electrons and other charges of the atoms and molecules that compose the material, causing them to move about. For example, this interaction alters the motion of the wave, changing its speed or wavelength.

In this framework, with employment of metamaterial technology novel approaches for UWB antennas design are proposed as remaining compact antennas dimensions. Proposed approaches have advantages such as easy integration and implementation, low cost, lower time requirement for fabrication, feasible, and practical.

Section 2 describes the operation and design principles of CRLH-TL corresponding to directive proposed unit cell of the antennas. The design approach consists of basic considerations and investigated structures, and guidelines for the UWB antennas design are presented in Sections 3 and 4, respectively. Details of the proposed antennas design will be illustrated in Section 5, as the first part of this section will propose $\mathbf{O}$-formed antenna composed of four unit cells and the second part of Section 5 presents bandwidth increment of the antenna composed of six $\mathbf{O}$-shaped unit cells. Results of the recommended antennas will be provided in the future section. Afterwards, advantages of the UWB miniature antennas based on CRLH-TLs are demonstrated in Section 7. Finally, Conclusion is given in Section 8.

\section{CRLH-TL Directive Proposed Unit Cell}

The CRLH-TL is a periodic structure composed of cascaded unit cells. Figure 2 shows a typical $\mathbf{O}$-formed gap capacitance/spiral, rectangular, and via inductors which proposed planar CRLH unit cell topology along with its lumped circuit model.

Such a TL exhibits the dispersion/attenuation relation [6]

$$
\begin{aligned}
\operatorname{Cos}[(\beta-j \alpha) p] & =1+\frac{Z(\omega) Y(\omega)}{2} \\
& =1-\frac{\left(\omega^{2}-\omega_{\mathrm{se}}^{2}\right)\left(\omega^{2}-\omega_{\mathrm{sh}}^{2}\right)}{2 \omega^{2} \omega_{R}^{2}},
\end{aligned}
$$

with

$$
\begin{gathered}
Z(\omega)=j\left(\omega L_{R}-\frac{1}{\omega C_{L}}\right), \\
Y(\omega)=j\left(\omega C_{R}-\frac{1}{\omega L_{L}}\right), \\
\omega_{\mathrm{se}}^{2}=\frac{1}{L_{R} C_{L}}, \\
\omega_{\mathrm{sh}}^{2}=\frac{1}{L_{L} C_{R}}, \\
\omega_{R}^{2}=\frac{1}{L_{R} C_{R}} .
\end{gathered}
$$

Under the so-called balanced condition, that is, $L_{R} C_{L}=$ $L_{L} C_{R}, \omega_{\mathrm{se}}=\omega_{\mathrm{sh}} \equiv \omega_{0}\left(\omega_{0}\right.$ is transition frequency from LH region to $\mathrm{RH}$ region, as follows),

$$
\begin{aligned}
\omega_{0}^{\text {Unbalanced }} & =\frac{1}{\sqrt[4]{L_{R} C_{R} L_{L} C_{L}}} \frac{L_{R} C_{L}=L_{L} C_{R}}{\longrightarrow} \omega_{0}^{\text {Balan }} \\
& =\frac{1}{\sqrt{L_{R} C_{L}}}=\frac{1}{L_{L} C_{R}}
\end{aligned}
$$

and under this condition, the function $\omega(\beta)$ can be derived from the general relation (2) as

$$
\omega(\beta)=\sqrt{\omega_{0}^{2}+\omega_{R}^{2} \operatorname{Sin}^{2} \frac{P \beta}{2}}+\omega_{R} \operatorname{Sin} \frac{P \beta}{2} .
$$

Due to the fact that the size $p$ of the unit cell is strongly subwavelength, in the frequency range of operation $\left(p / \lambda_{g} \ll\right.$ 1), CRLH structures behave as a uniform transmission media. Therefore all the concepts of uniform traveling-wave and resonant-type structures can be transposed to such metamaterial structures, while they offer in addition unique properties not available in conventional systems.

Limited space or low operating frequencies demand antennas which are quite small compared to the free space 


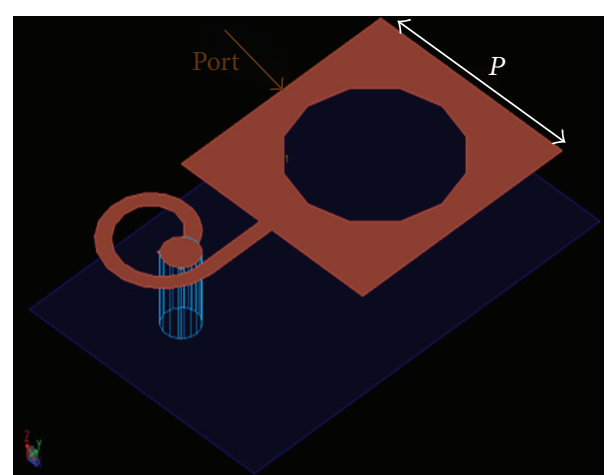

(a) $\mathbf{O}$-formed unit cell composed of $\mathbf{O}$-shaped gap capacitance acts like left-handed capacitance $\left(C_{L}\right)$, and spiral inductor connected to ground plane through a metallic via hole that will be established left-handed inductor $\left(L_{L}\right)$

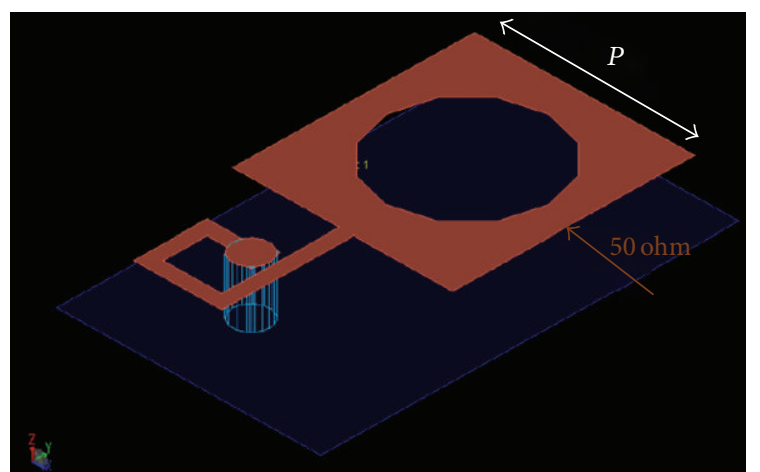

(b) $\mathbf{O}$-shaped unit cell composed of $\mathbf{O}$-formed gap capacitance that performs as series capacitance $\left(C_{L}\right)$ and rectangular inductor which through metallic via hole connected to ground plane as do like shunt inductor $\left(L_{L}\right)$

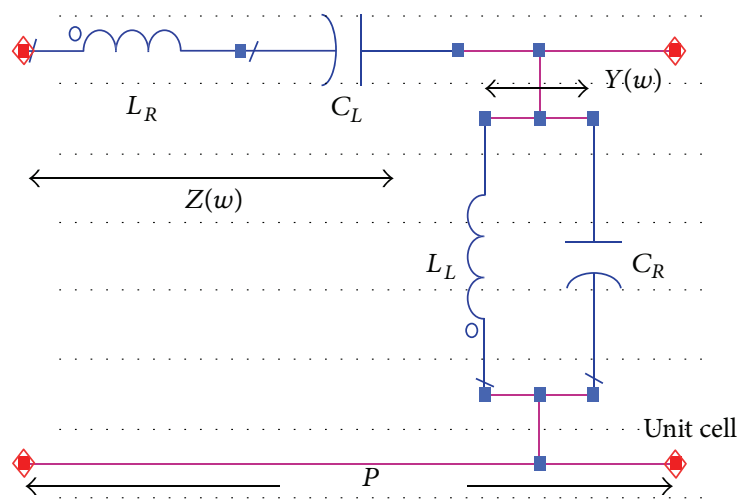

(c)

FIgURE 2: Typical CRLH planar unit cell topology along with its circuit model. The series capacitance $C_{L}$ is implemented as $\mathbf{O}$-shaped gap capacitance and the shunt inductance $L_{L}$ as spiral and rectangular inductors which connected to ground plane through metallic via holes. The substrate FR_4 with height $h=0.8 \mathrm{~mm}, \varepsilon_{r}=4.6$ and $\tan \delta=1 \times 10^{-3}$ has been used in all of the structures of this paper.

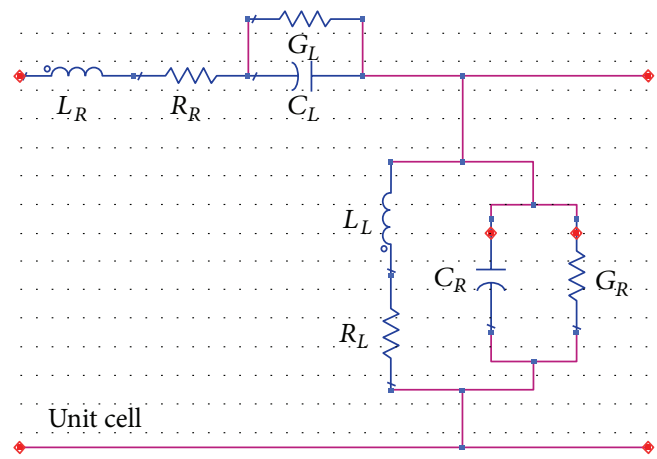

(a)

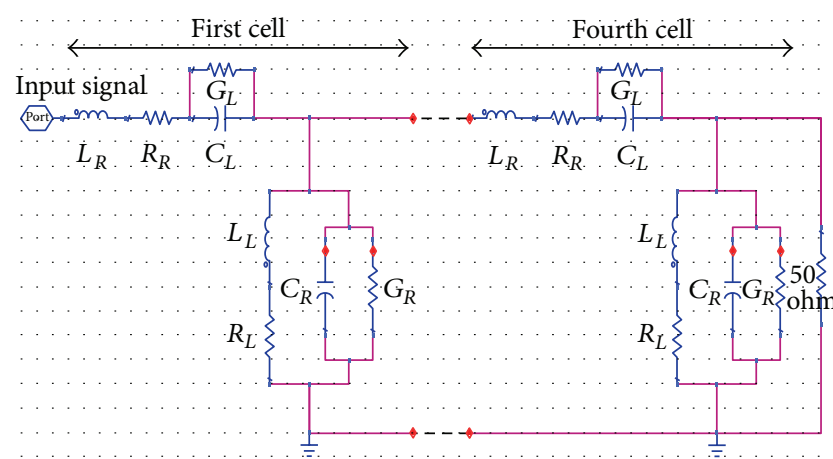

(b)

FIGURE 3: Equivalent circuit model of the $\mathbf{O}$-formed antenna constructed of four unit cells: (a) for one unit cells, (b) for entire structure.

wavelength. Planar patch antennas are very attractive from the point of fabrication and system integration despite being limited in size to a half of the substrate wavelength because of their resonant nature. The principle of reactive loading of patch antennas to change their pattern, impedance, resonant frequency, and so forth is known for a long time [7].
Recently $L-C$ loaded planar lines (LCPL) have attracted attention because of their special properties. In this concept series capacitors and shunt inductors are used to synthesize a medium with simultaneously negative permeability and permittivity ( $\varepsilon$ and $\mu<0$ ), the so-called left-handed (LH) metamaterials [8]. Some applications have demonstrated 


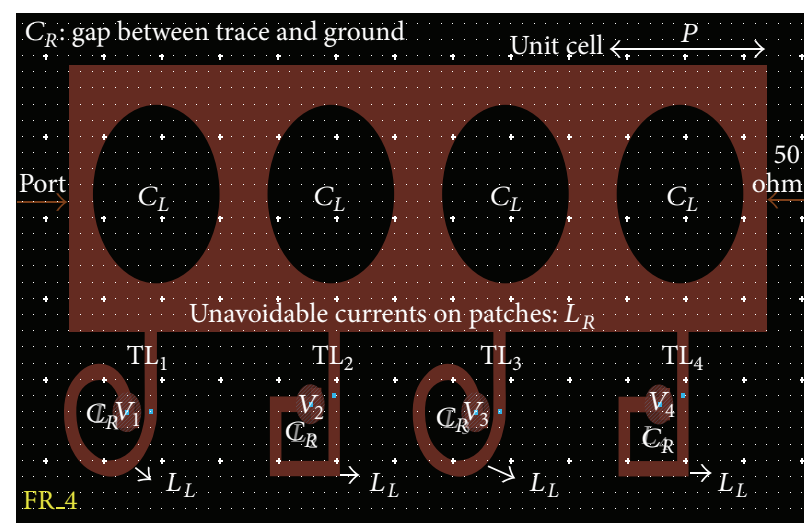

(a)

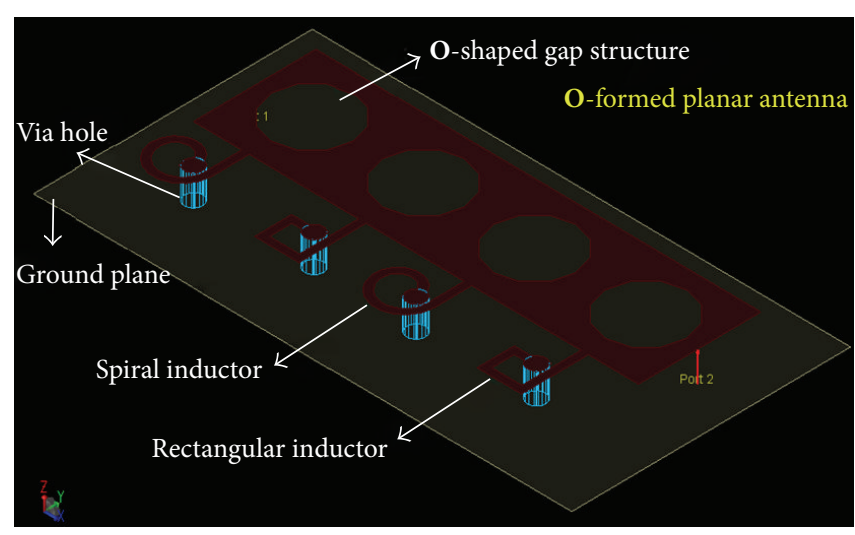

(b)

FIGURE 4: Layout of four unit cell of the proposed $\mathbf{O}$-shaped antenna structure: (a) top view, (b) isometric view.

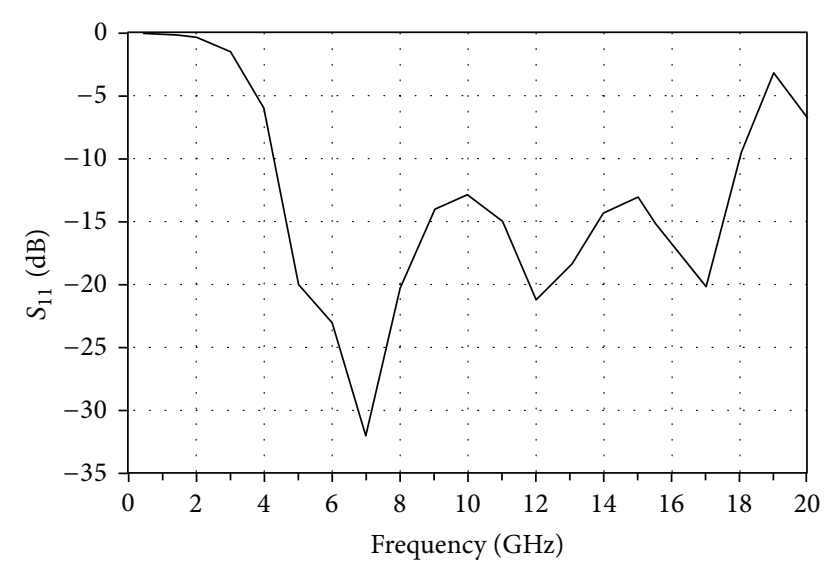

FIGURE 5: Simulated return loss bandwidth $\left(S_{11}<-10 \mathrm{dBi}\right)$ of the recommended antenna.

the superior properties of devices build on these materials $[8,9]$. This paper investigates the application of this concept for design of compact antennas by using the high negative value of the wave number $\beta$ to shrink the physical length of two different types of planar antennas.

\section{Design Approach}

3.1. Basic Considerations. As shown in [9] the wave number $\beta_{\mathrm{LCPL}}$ of a periodically $L-C$ loaded planar transmission line can be written as

$$
\beta_{\mathrm{LCPL}}=\omega \cdot \sqrt{L_{\mathrm{PL}} C_{\mathrm{PL}}}-\frac{1}{\omega \sqrt{L C}}
$$

where $L_{\mathrm{PL}}$ and $C_{\mathrm{PL}}$ represent the distributed capacitances and inductances of a planar line. The second term in (6) accounts for a periodical reactive loading of the line with lumped inductors $L$ and capacitors $C$. The wave number $\beta_{\mathrm{LCPL}}$ becomes negative for low frequencies and approaches
$\beta_{\mathrm{PL}}=\omega \cdot \sqrt{L_{\mathrm{PL}} C_{\mathrm{PL}}}$ if the frequency is significantly increased. Relating $\beta_{\mathrm{LCPL}}$ to the wave number $\beta_{\mathrm{PL}}$ leads to

$$
\frac{\beta_{\mathrm{LCPL}}}{\beta_{\mathrm{PL}}}=1-\frac{1}{\omega^{2} \cdot \sqrt{L C L_{\mathrm{PL}} C_{\mathrm{PL}}}} .
$$

With proper chosen values for $L, C, L_{\mathrm{PL}}$, and $C_{\mathrm{PL}}$

$$
\left|\beta_{\mathrm{LCPL}}\right| \gg\left|\beta_{\mathrm{PL}}\right| \longleftrightarrow \lambda_{\mathrm{LCPL}} \ll \lambda_{\mathrm{PL}}
$$

can be achieved in a certain frequency range.

For a planar patch antenna, the $n$th resonant mode is related to a patch length of $n \cdot \lambda_{\mathrm{PL}} / 2$. Therefore the physical length of an $L-C$ loaded patch antenna $l_{p}$ is

$$
l_{p}=\frac{n \cdot \lambda_{\mathrm{LCPL}}}{2} .
$$

Considering (8) and (9) the possibility to shrink the physical dimensions of a patch antenna metallization by the integration of $L-C$ elements into the planar line becomes obvious.

3.2. Investigated Structures. Two different antenna concepts-both based on periodically $L-C$ loaded planar lineshave been investigated. Figure 2 shows a schematic drawing of a planar patch and the slotted cavity approach. Inductances are realized by spiral inductors, rectangular inductors, and metallic via holes and capacitors that are implemented by gap sections printed into the planar patches. A dielectric sheet not visible in this drawing carries the metal. Both layout structures can also be seen as a cut out of a so-called "highimpedance surface" [10] where the calculation approach with lumped elements has already been proven.

The here called cavity antennas are derived from patch antennas by short circuiting the radiating slots by several spiral inductors, rectangular inductors, and metallic via holes. Sources radiation becomes the $\mathbf{O}$-formed gap capacitors in the center of the structures.

In analogy to (9) and considering the boundary conditions at the end of the planar line resonances can be observed for

$$
l_{p}=m \cdot \lambda_{\mathrm{LCPL}}
$$




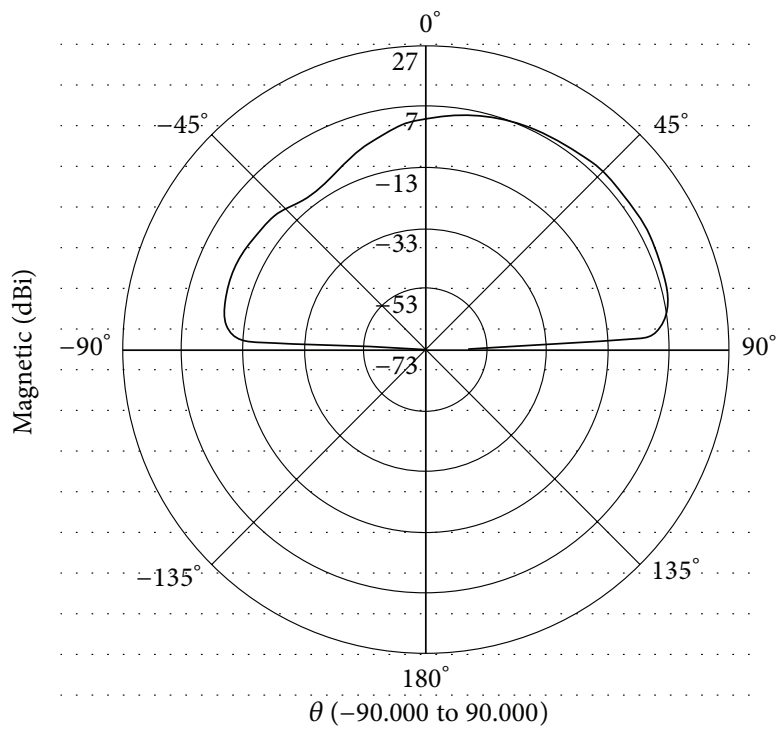

(a)

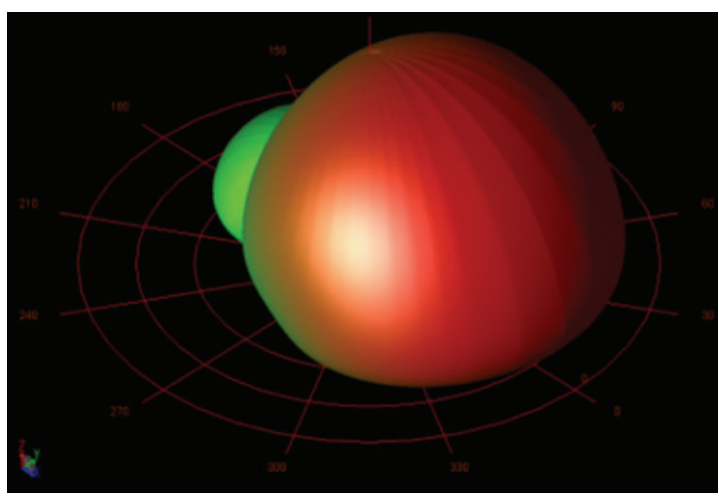

(b)

FIGURE 6: Simulated radiation gain patterns in elevation plane $\left(\Phi=0^{\circ}\right)$ and at operation frequency $f=12 \mathrm{GHz}$. (a) Two-dimensional (2D) case, (b) three-dimensional (3D) case.

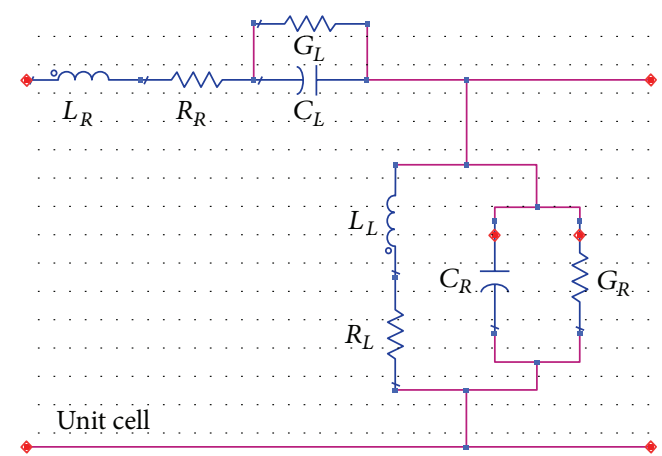

(a)

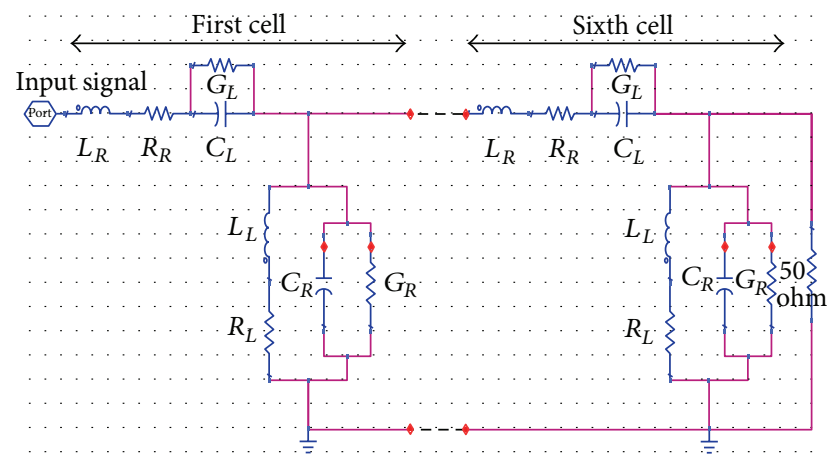

(b)

FIGURE 7: Equivalent circuit model of the second proposed antenna composed of six unit cells: (a) for one unit cell, (b) for whole structure.

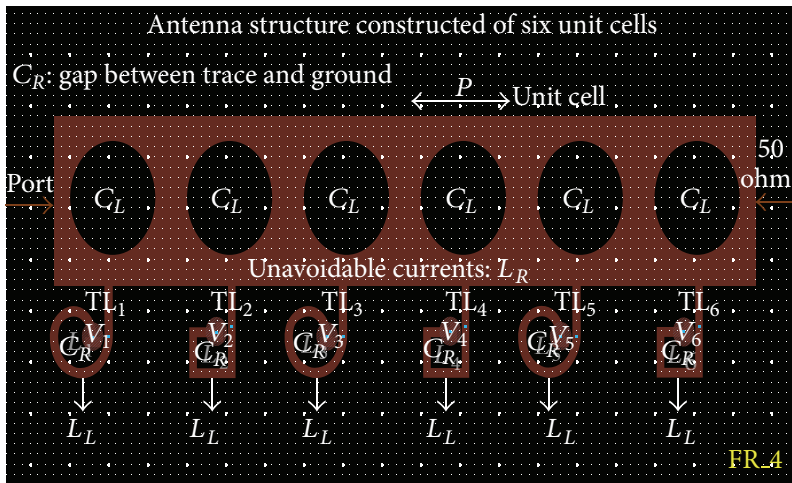

(a)

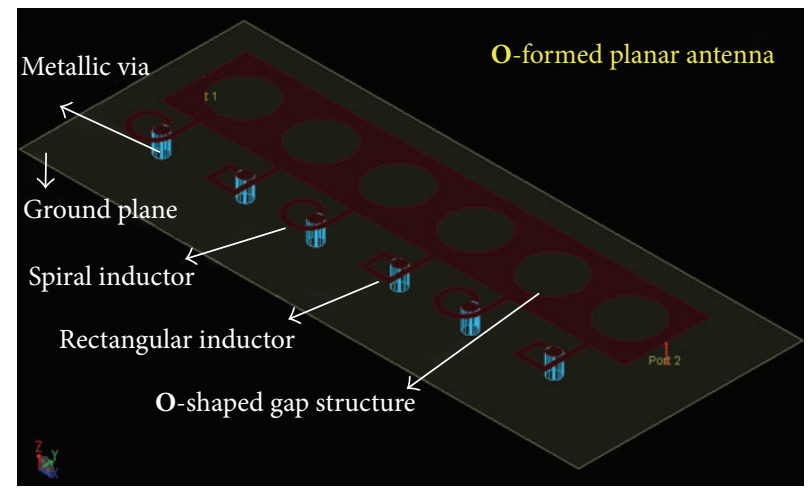

(b)

FIGURE 8: Arrangement of elements of the latter antenna composed of six O-formed unit cells: (a) top view, (b) isometric view. 


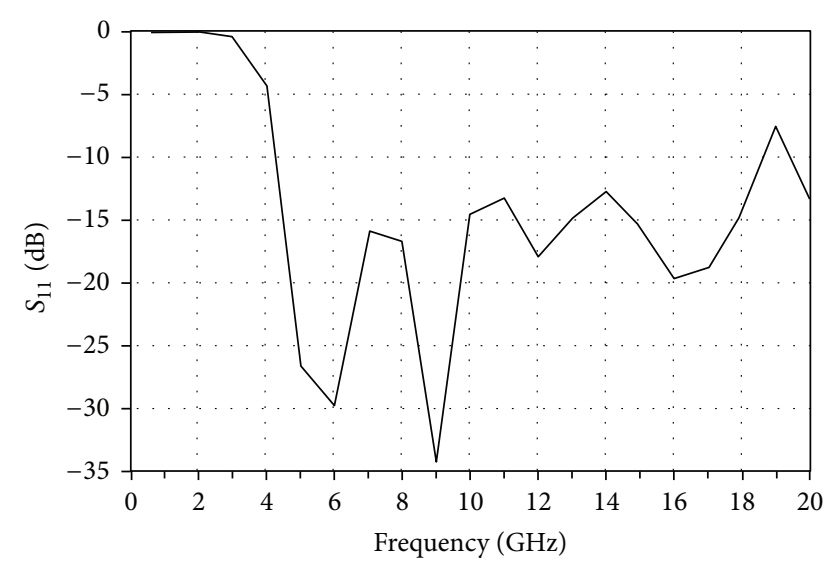

Figure 9: Simulated reflection coefficient $\left(S_{11}\right.$ parameter) of the $\mathbf{O}$ shaped antenna composed of six unit cells.

According to conventional patches both antennas are supposed to radiate linear polarized waves.

\section{Guidelines for the UWB Antenna Design}

The transmission coefficient of the antenna system is an important frequency domain indicator of the time domain performance of a UWB antenna [11]. The points summarized in below are guidelines for the UWB antenna design.

(i) Travelling wave antennas or antennas having low $Q$ can be very broad in band.

(ii) Antennas incorporating tapers or rounded edges tend to give broad bandwidths because surface currents have a smooth path to follow [12].

(iii) Linearly polarized transmit and receive antennas are the simplest to implement in a compact planar package.

(iv) Minimizing the thickness of the substrate and using low loss materials maximizes bandwidth and radiation efficiency.

(v) Using the printed planar technique within radiation patches with minimizing acceptable distance between gap edges leads to extension of the antenna bandwidth.

In this framework, we used these proposed approaches for enhancement of the antennas bandwidth.

\section{Realization of the Proposed Antennas}

Gold of the paper, consist of design and modeling of UWB antennas with shrink the physical dimensions accompanying good radiation characteristics. In design procedures, utilized of the recommended novel approaches based on metamaterial transmission line technology, slot cavities as acts like series capacitances. Also, suitable chosen and employment of the inductive components that contributing in the antennas structures such as spiral inductors, rectangular inductors and shorting via holes attending optimized values as perform shunt inductors roles.

5.1. UWB MTM Cavity Antenna with Shrinking the Physical Size. Design procedure of the proposed antenna is based on a simple topology that incorporates printed planar patches and spiral and rectangular inductors accompanying metallic vias connected to ground plane. This topology makes it possible to combine the antenna with integrated RF electronics. We employed electromagnetic band gap (EBG) unit to act as the radiation unit, which is the simplest way to achieve the series capacitance. With employment of the printed planar technique into radiation patches gap capacitance is created which lead to foot print area reduction, in additions; with choosing a smaller value of the gap capacitance made into radiation patches we can obtain wide bandwidth, and therefore, our antenna has a small size and broad bandwidth. Also beside the small size and the broad bandwidth properties, the radiation characteristics of the antenna are most the important subject. With utilizing of the four unit cells in form $\mathbf{O}$-shaped gap structure, the larger aperture size, the uniform excitation mechanism by employing of two ports as firs port is excited with input signal, and second port matched $50 \mathrm{Ohm}$ load impedance, using suitable structural parameters and using proper inductive elements such as spiral and rectangular inductors with one turn and their optimized dimensions attending vertical via holes with optimized diameters and good realization of the $\mathbf{O}$ shaped gaps; with improvement distance between gap edges, appropriate radiation performances can be achieved. The novel small size ultra wideband antenna with appropriate radiation performances, presented in here, is based on four simplified mushroom structure unit cells of the CRLH-TL, with each unit cell including a rectangular radiation patch with one printed $\mathbf{O}$-formed gaps into radiation patch and a spiral or rectangular inductor connected to ground plane through a metallic via. The equivalent circuit model of the antenna structure is shown in Figure 3. Figure 4 shows the geometric structure of the proposed antenna. In each unit cell, the printed $\mathbf{O}$-shaped gap into rectangular radiation patch establishes series capacitance $\left(C_{L}\right)$, and spiral or rectangular inductor accompanying metallic via acts like shunt inductance $\left(L_{L}\right)$. The TLs possess the right-handed parasitic effects that can be seen as shunt capacitance $\left(C_{R}\right)$ and series inductance $\left(L_{R}\right)$. The shunt capacitance $C_{R}$ mostly comes from the gap capacitance between the patch and the ground, and unavoidable current flows on the patch and establishes series inductance $L_{R}$ which indicates that these capacitance and inductance cannot be ignored.

Obviously in Figure 3, CRLH propagation along a given direction can be modeled by the 8-parameter unit cell lumped element circuit. This model essentially exhibits a series capacitance $C_{L}$ and a shunt inductance $L_{L}$ (left-handed $(\mathrm{LH})$ ), corresponding to negative permeability and negative permittivity, respectively, but also includes a series inductance $L_{R}$ and a shunt capacitance $C_{R}$ (right-handed $(\mathrm{RH})$ ) associated with the magnetic and electric fluxes, respectively, intrinsic to any TL structures, and corresponding to positive permeability and permittivity, respectively (11). In addition to 


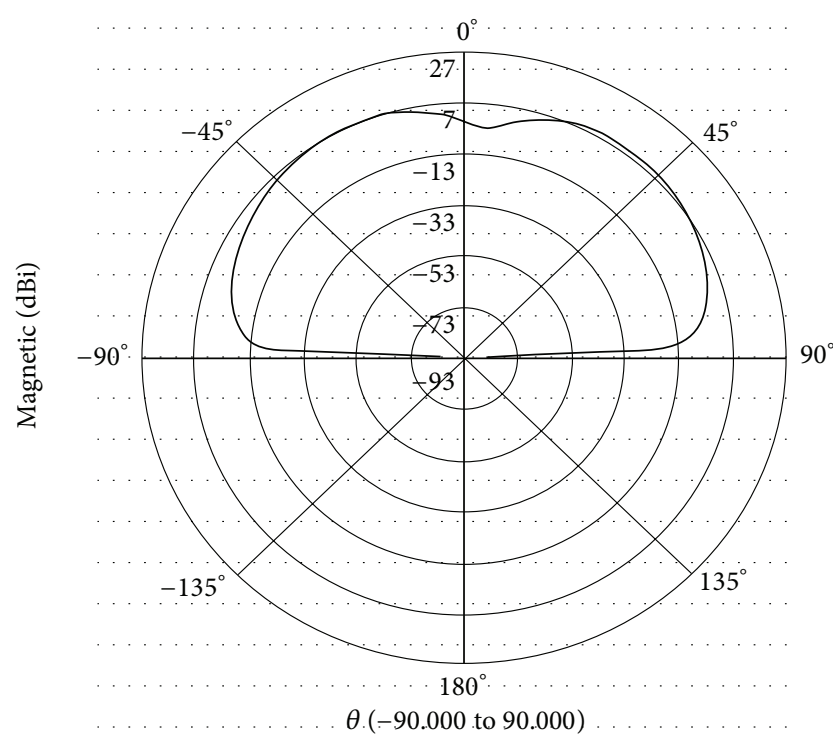

(a)

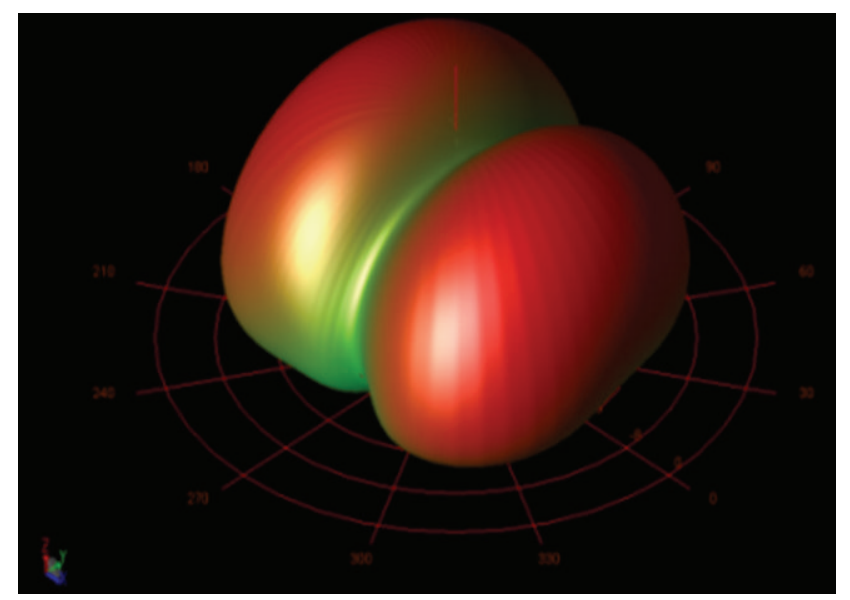

(b)

FIGURE 10: Simulated radiation gain patterns of the second proposed antenna composed of six unit cells in elevation plane $\left(\Phi=0^{\circ}\right)$ and at operation frequency $f=16 \mathrm{GHz}$. (a) Two-dimensional (2D) case, (b) three-dimensional (3D) case.

these four reactive parameters, one has the conventional lossy parameters $R_{R}$ and $G_{R}(\mathrm{RH})$ and the lossy parameters $G_{L}$ and $R_{L}(\mathrm{LH})$, which account for the dielectric loss associated with $C_{L}$ and the ohmic loss associated with $L_{L}$, respectively, and which mostly represent radiation in antenna applications:

$$
\begin{aligned}
& \mu=\frac{Z}{j \omega}=L_{R}-\frac{1}{\omega^{2} C_{L}}, \\
& \varepsilon=\frac{Y}{j \omega}=C_{R}-\frac{1}{\omega^{2} L_{L}} .
\end{aligned}
$$

In this structure, we used the uniform excitation mechanism by utilizing port 1 and port 2 , whereas port 1 is excited with input signal and port 2 is matched with $50 \mathrm{ohm}$ load impedance. Series capacitance can be adjusted by varying distance between printed $\mathbf{O}$-shaped gap edges. This feature provides another important parameter that can be used to change the performance of the antenna. We used the printed planar approach to produce gap capacitance and smaller values of printed gaps into rectangular patches of the radiated patches and also employed suitable structural parameters with their optimized values accompanying uniform excitation mechanism which provides a small size and ultrawideband (UWB) antenna with appropriate radiation characteristics. The CRLH MTM antenna is designed on an FR_4 substrate with thickness of $h=0.8 \mathrm{~mm}$, dielectric constant of $\varepsilon_{r}=4.6$, and $\tan \delta=1 \times 10^{-3}$. The physical size of this antenna is $12 \mathrm{~mm} \times 5.1 \mathrm{~mm} \times 0.8 \mathrm{~mm}\left(0.17 \lambda_{0} \times\right.$ $0.07 \lambda_{0} \times 0.01 \lambda_{0}$, where $\lambda_{0}$ is the free space wavelength at $4.3 \mathrm{GHz}$ ). Obviously in Figure 5, this antenna has $13.7 \mathrm{GHz}$ bandwidth from $4.3 \mathrm{GHz}$ to $18 \mathrm{GHz}$, which corresponds to $122.86 \%$ bandwidth. This make the proposed antenna had to be broad bandwidth accompanying small size enough to fit on the communication devices, and this antenna is much smaller in the size and wider in the bandwidth than conventional compact and UWB antennas. In addition, the maximum gain and radiation efficiency occur at $f=12 \mathrm{GHz}$ which are equal to $7.43 \mathrm{dBi}$ and $84.5 \%$, respectively, which are displayed in Figure 6. Presented antenna is attractive and suitable for modern transceivers, wireless communication systems, and UWB applications.

\subsection{Bandwidth Increment Design for Miniature Antenna} Based on CRLH-TLs. Design procedure of this antenna is completely similar to design procedure of the previous antenna but with the difference that in the latter antenna design number of unit cells from four unit cells to six unit cells is increased, as this increase caused enhancement of the antenna bandwidth. Equivalent circuit model and arrangement of elements of the second proposed antenna are shown in Figures 7 and 8, respectively.

This antenna is composed of six simplified mushroom structure unit cells as in each unit cell $C_{L}$ and $L_{L}$ are implemented by $\mathbf{O}$-formed gap capacitance and spiral or rectangular inductor connected to ground plane through metallic via hole, respectively, and $C_{R}$ and $L_{R}$ are established by RH parasitic effects. Similar to the first antenna, latter antenna is designed on an FR_4 substrate with thickness of $h=0.8 \mathrm{~mm}$, dielectric constant of $\varepsilon_{r}=4.6$, and $\tan \delta=1 \times$ $10^{-3}$. The physical length, width, and height of the antenna are $18 \mathrm{~mm}, 5.1 \mathrm{~mm}$, and $0.8 \mathrm{~mm}$ or $0.25 \lambda_{0}, 0.07 \lambda_{0}$, and $0.01 \lambda_{0}$ in the free space wavelength at $f=4.3 \mathrm{GHz}$, respectively. According to Figure 9, the antenna has $14.3 \mathrm{GHz}$ bandwidth, from $4.3 \mathrm{GHz}$ to $18.6 \mathrm{GHz}$, which corresponds to $124.89 \%$ workable bandwidth. Radiation gains and efficiencies of the proposed antenna vary from $-4 \mathrm{dBi}$ to $6.03 \mathrm{dBi}$ and from $5.56 \%$ to $57.57 \%$, respectively, and hence the highest gain and radiation efficiency are $6.03 \mathrm{dBi}$ and $57.57 \%$, respectively, 


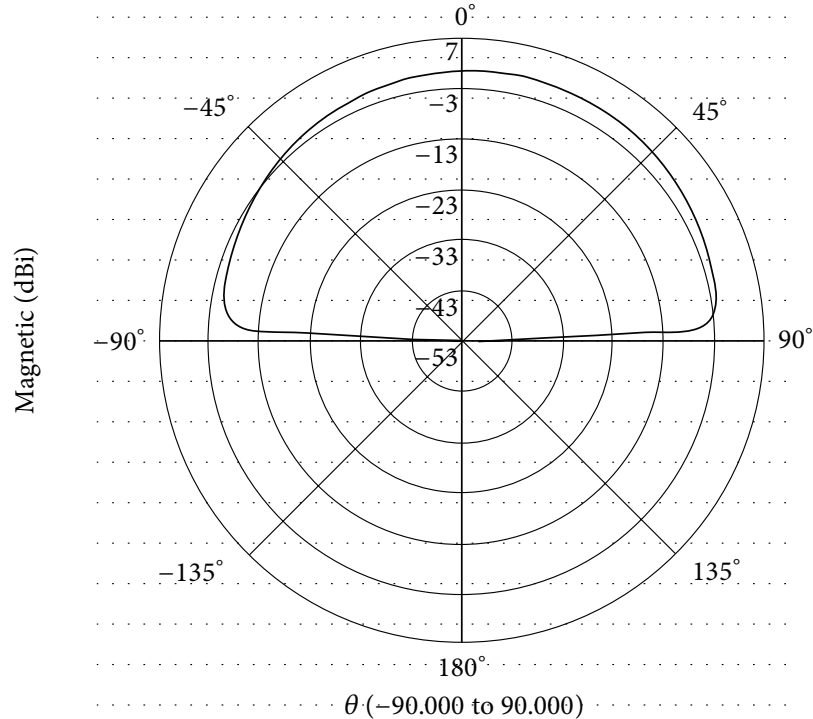

(a)

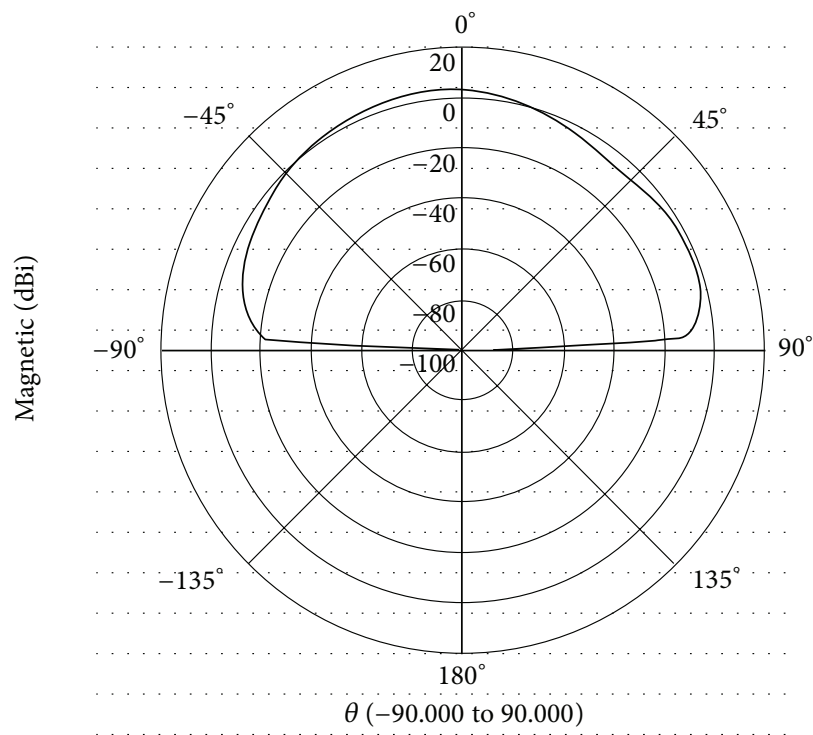

(c)

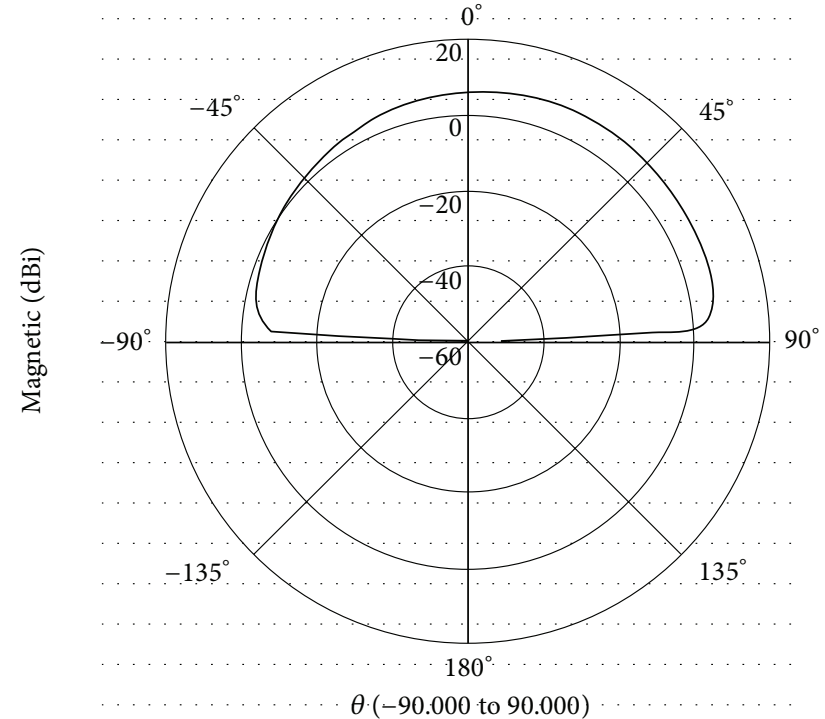

(b)

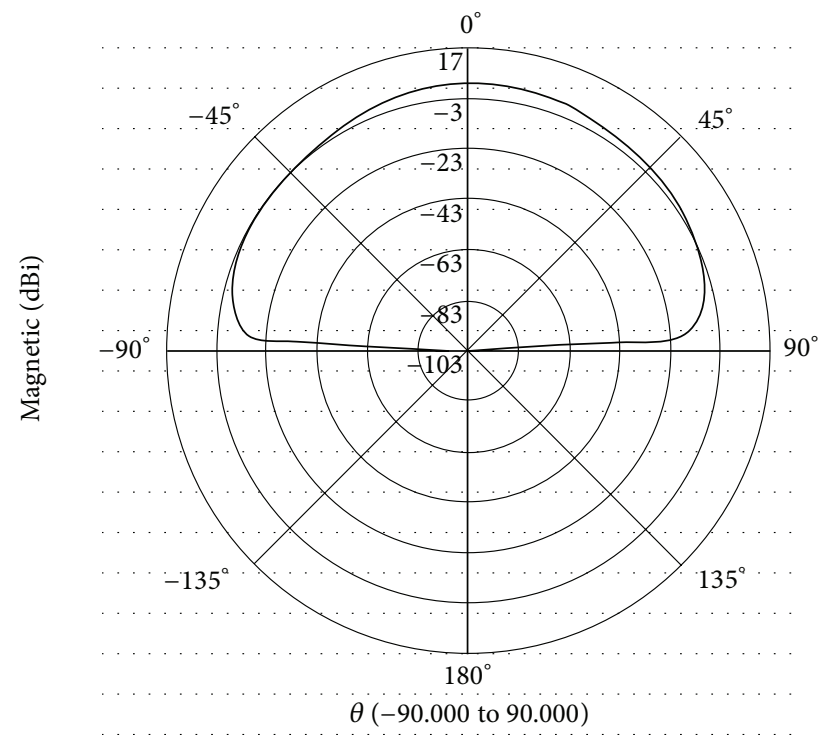

(d)

FIGURE 11: Simulated two-dimensional (2D) radiation gain patterns of the proposed antenna composed of four unit cells in elevation plane $\left(\Phi=0^{\circ}\right)$ and at operation frequencies: (a) at $4.3 \mathrm{GHz}$, (b) at $7 \mathrm{GHz}$, (c) at $17 \mathrm{GHz}$, (d) at $18 \mathrm{GHz}$.

that happen at $16 \mathrm{GHz}$. The simulated radiation gain patterns at $16 \mathrm{GHz}$ are exhibit in Figure 10. As obvious results show, proposed antenna may be good nominee for portable devices, modern wireless communications and transceivers, ultra wide band (UWB) applications, and realizations of apparatus and systems where small area and broad bandwidth are required.

\section{Obtained Results of the Proposed Cavity Antennas Based on CRLH Transmission Lines}

The antennas were designed and modeled on FR_4 substrates with $\varepsilon_{r}=4.6$, thickness of $h=0.8 \mathrm{~mm}$, and $\tan \delta=1 \times 10^{-3}$.
Each unit cell of the proposed antennas occupies only $3 \times$ $5.1 \times 0.8 \mathrm{~mm}^{3}$ overall sizes of the proposed antennas are $12 \times$ $5.1 \times 0.8 \mathrm{~mm}^{3}$, and $18 \times 5.1 \times 0.8 \mathrm{~mm}^{3}$, and each of antennas is composed of four and six $\mathbf{O}$-formed unit cells, respectively. According to these dimensions, proposed antennas have very smaller size in comparison to conventional miniature antennas. The simulated results were obtained using Agilent ADS full-wave simulator. As illustrated in Figures 5 and 9, the simulated return loss of bandwidths $\left(S_{11}<-10 \mathrm{~dB}\right)$ of the O-shaped antennas composed of four unit cells is $13.7 \mathrm{GHz}$ $(4.3-18 \mathrm{GHz})$ and combined of six unit cells is $14.3 \mathrm{GHz}$ $(4.3-18.6 \mathrm{GHz})$, which these correspond to approximately $123 \%$ and $125 \%$ practical impedance bandwidths, respectively, which are more than conventional UWB antennas. 


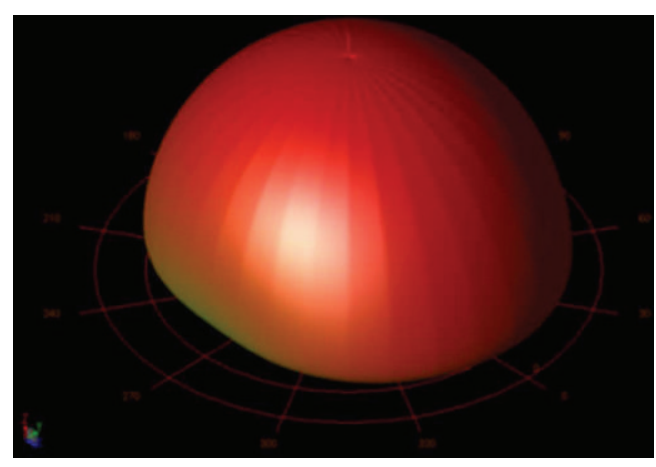

(a)

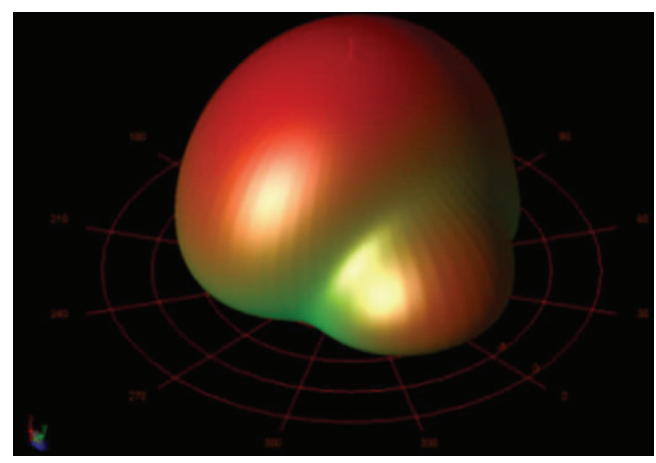

(c)

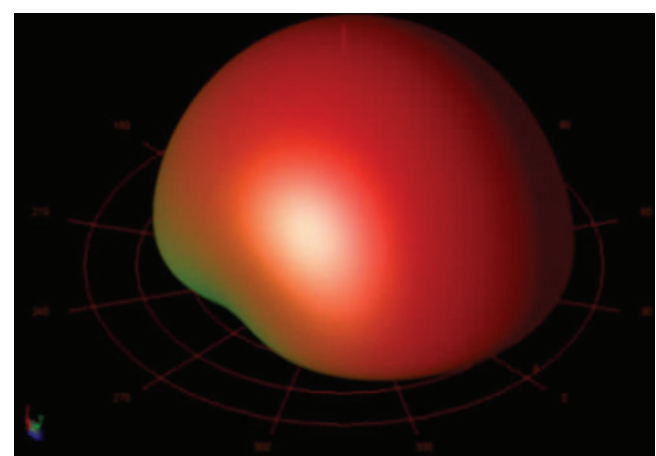

(b)

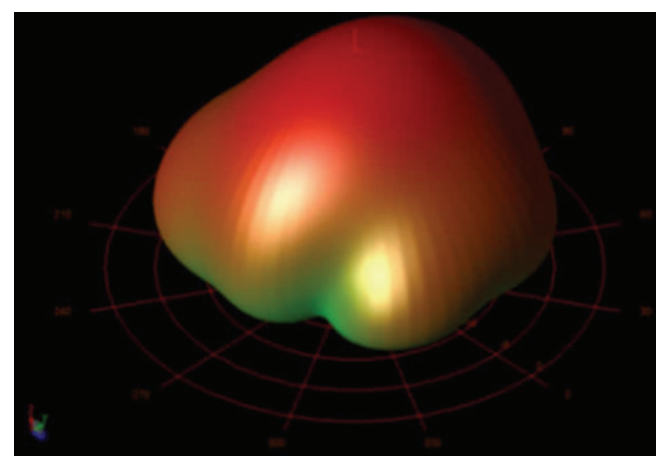

(d)

FIGURE 12: Simulated three-dimensional (3D) radiation gain patterns of the proposed antenna composed of four unit cells in elevation plane $\left(\Phi=0^{\circ}\right)$ and at operation frequencies: (a) at $4.3 \mathrm{GHz}$, (b) at $7 \mathrm{GHz}$, (c) at $17 \mathrm{GHz}$, (d) at $18 \mathrm{GHz}$.

TABLE 1: Radiation characteristics of two compact antennas in comparison to the proposed miniature antennas.

\begin{tabular}{lcccc}
\hline Parameters & {$[13]$} & {$[14]$} & First antenna & Second antenna \\
\hline Gain $(\mathrm{dBi})$ & 0.6 & 0.45 & 7.43 & 6.03 \\
Bandwidth (GHz) & $1-2$ & $0.8-2.5$ & $4.3-18$ & $4.3-18.6$ \\
Efficiency (\%) & 26 & 53.6 & 84.5 & 57.57 \\
\hline
\end{tabular}

The simulated two-dimensional (2D) and three-dimensional (3D) radiation gain patterns of the first antenna at operation frequencies are exhibited in Figures 11 and 12, respectively. Also the same parameters of the latter recommended antenna in $2 \mathrm{D}$ and $3 \mathrm{D}$ cases at operation frequencies are exhibited in Figures 13 and 14, respectively. Obviously, the radiation patterns have unidirectional characteristics. According to Figure 11 the simulated gains and radiation efficiencies of the $\mathbf{O}$-shaped antenna composed of four unit cells at 4.3, 7,17 , and $18 \mathrm{GHz}$ are $0.1 \mathrm{dBi}$ and $1.5 \%, 2.2 \mathrm{dBi}$ and $30 \%$, $3.36 \mathrm{dBi}$ and $38.22 \%$, and $3.85 \mathrm{dBi}$ and $32.75 \%$, respectively, and according to Figure 13 these parameters for $\mathbf{O}$-shaped antenna composed of six unit cells at $4.3,6,9$, and $18.6 \mathrm{GHz}$ are $-4 \mathrm{dBi}$ and $5.56 \%, 0.42 \mathrm{dBi}$ and $23.61 \%, 1.84 \mathrm{dBi}$ and $42.73 \%$, and $1.06 \mathrm{dBi}$ and $23.42 \%$, respectively. To validate the design procedures, the proposed antennas were compared with several compact and UWB antennas, and their radiation characteristics and their dimensions were summarized in Tables 1 and 2, respectively.
TABLE 2: Dimension of some of the UWB antennas in comparison to the proposed UWB antennas.

\begin{tabular}{lc}
\hline Some of the UWB monopole antennas & Size of antenna \\
\hline $\begin{array}{l}\text { Slotted planar binomial monopole } \\
\text { antenna [15] }\end{array}$ & $30 \times 27.4 \times 1 \mathrm{~mm}^{3}$ \\
$\begin{array}{l}\text { Slotted circular monopole antenna [16] } \\
\text { Slotted rectangular monopole antenna }\end{array}$ & $26 \times 27 \times 1 \mathrm{~mm}^{3}$ \\
[17] & $18 \times 20 \times 1 \mathrm{~mm}^{3}$ \\
Fork-shaped antenna [18] & $35 \times 30 \times 0.769 \mathrm{~mm}^{3}$ \\
Slotted arc-shaped edge rectangular & $24 \times 35 \times 0.8 \mathrm{~mm}^{3}$ \\
antenna [19] & $12 \times 5.1 \times 0.8 \mathrm{~mm}^{3}$ \\
First UWB antenna & $18 \times 5.1 \times 0.8 \mathrm{~mm}^{3}$ \\
\hline Second UWB antenna
\end{tabular}

\section{Privileges of the Suggested UWB Planar Antennas with Ultrashrinking of the Physical Size Based on CRLH MTM-TLS}

Proposed CRLH-based antennas are ultra wideband (UWB), low profile, and ultraminiature on a printed circuit board, and consist of superior radiation performances. In fact, the proposed CRLH-based antennas have broader bandwidth than conventional UWB antennas and are very smaller than conventional compact antennas while offering better performances. Furthermore, unlike conventional threedimensional (3D) antennas which must be designed, tooled, 


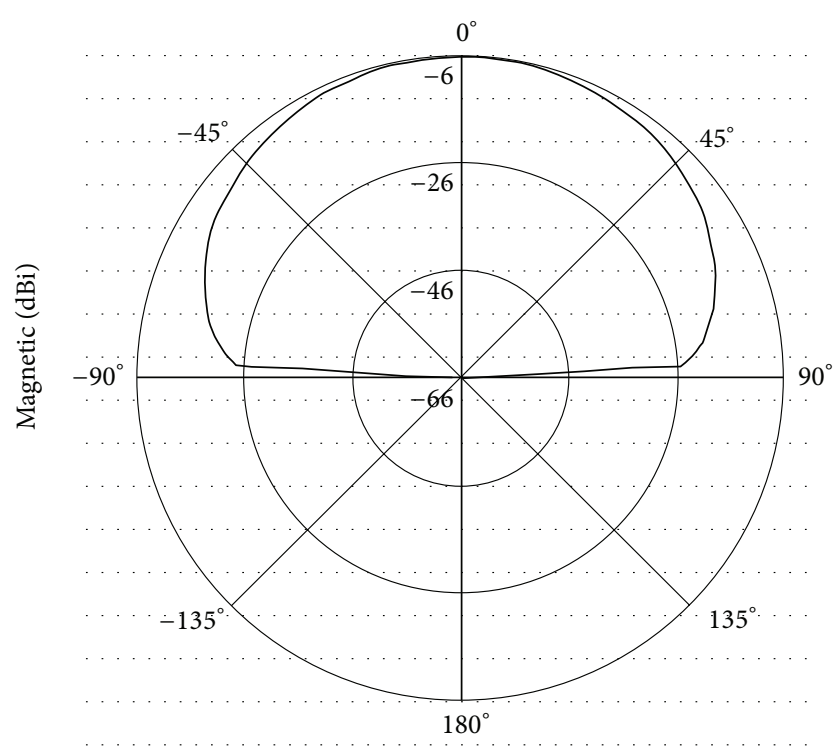

$\theta(-90.000$ to 90.000$)$

(a)

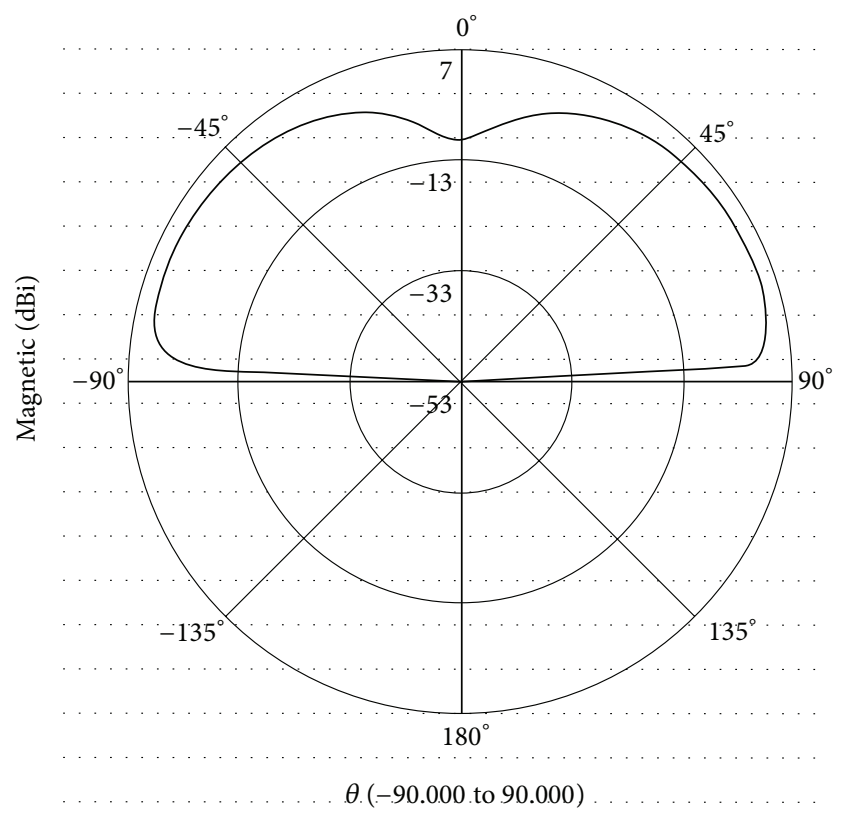

(c)

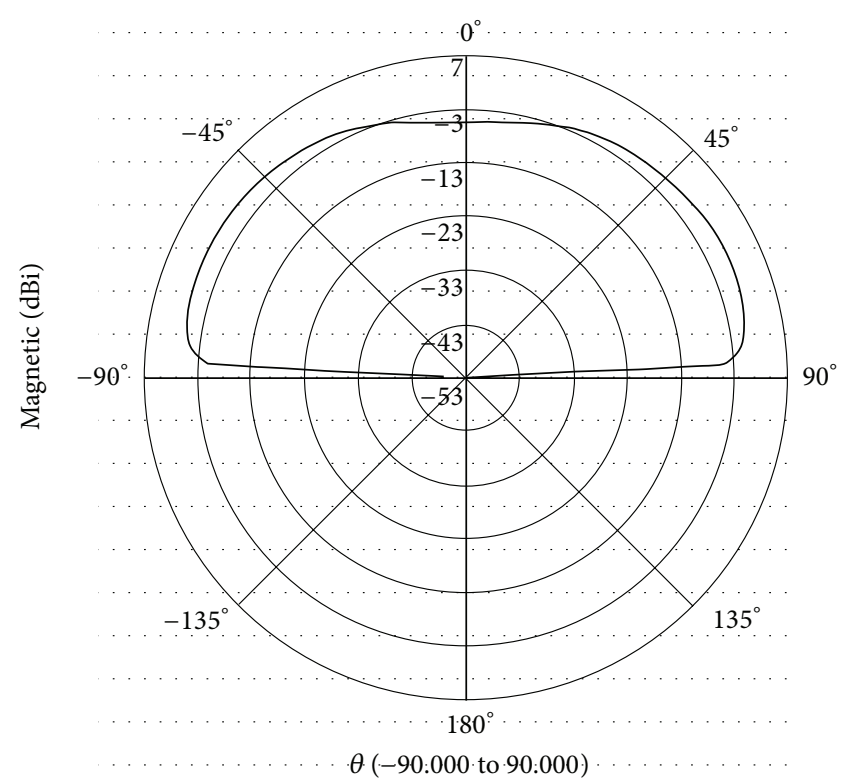

(b)

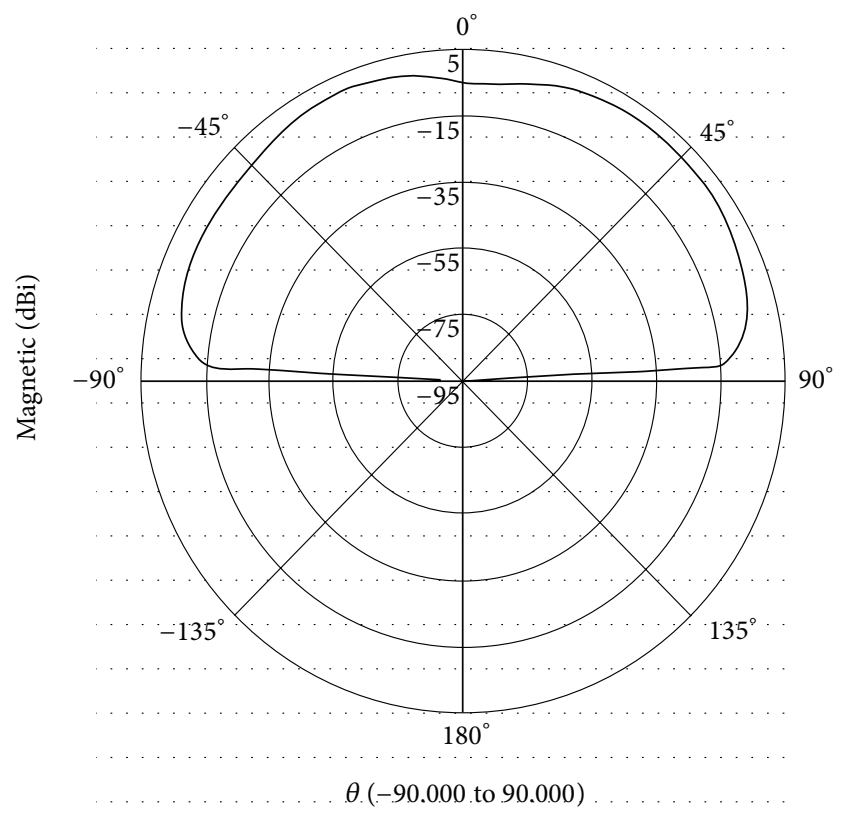

(d)

FIGURE 13: Simulated two-dimensional (2D) radiation gain patterns of the proposed antenna composed of six unit cells in elevation plane $\left(\Phi=0^{\circ}\right)$ and at operation frequencies: (a) at $4.3 \mathrm{GHz}$, (b) at $6 \mathrm{GHz},(\mathrm{c})$ at $9 \mathrm{GHz}$, (d) at $18.6 \mathrm{GHz}$.

and fabricated as a complex metal and plastic assembly, the proposed antennas shown in Figures 4 and 8 are simply designed, tooled, and fabricated in the three-dimensional (3D) configurations. Copper artwork is printed directly on a printed circuit board using standard printed circuit board manufacturing techniques. This offers manufacturers faster time to market and reduced bills of materials due to the simplified design. It also offers a greatly reduced need for fabrication and assembly of antenna components.
In addition, the CRLH-based antenna's ability to concentrate electromagnetic fields and currents near their antenna structures results in achieving better performance. Therefore, proposed UWB and ultracompact CRLH MTM planar antennas can be practical and feasible for commercial uses. CRLH-based shrinking antennas cover frequency bands from $4.3 \mathrm{GHz}$ to $18 \mathrm{GHz}$ and from $4.3 \mathrm{GHz}$ to $18.6 \mathrm{GHz}$ for microwave applications such as transceivers, telecommunication implementations, radar applications, location tracing, 


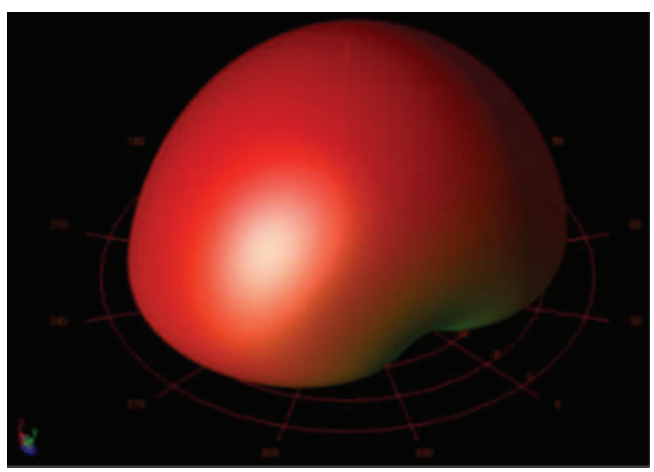

(a)

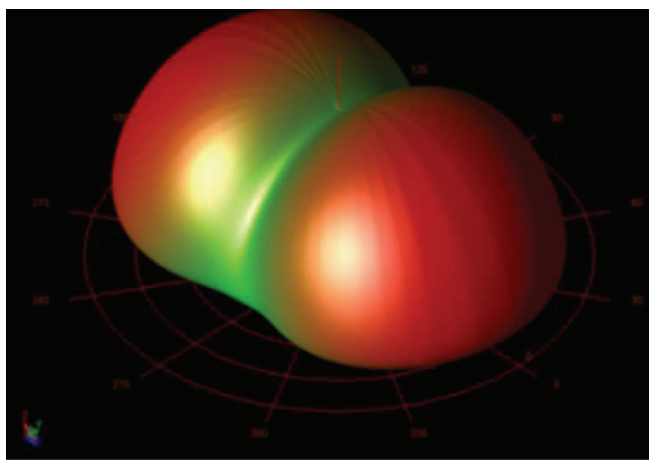

(c)

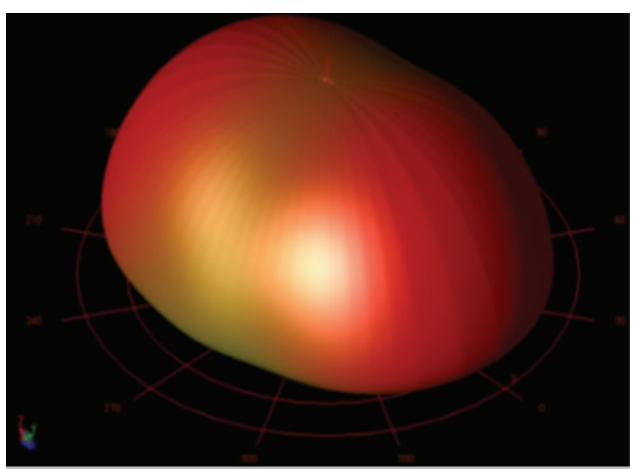

(b)

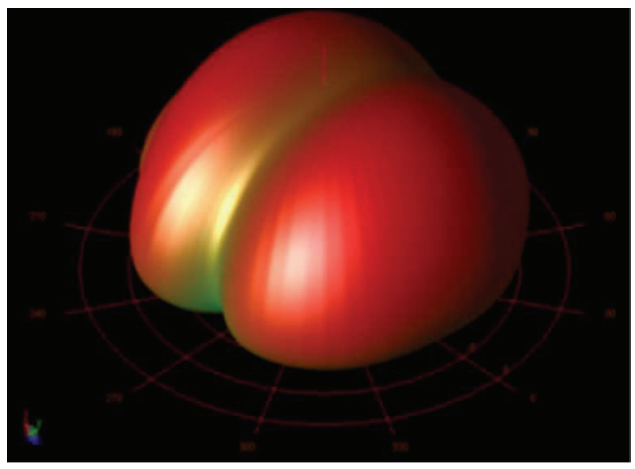

(d)

FIGURE 14: Simulated three-dimensional (3D) radiation gain patterns of the proposed antenna composed of six unit cells in elevation plane $\left(\Phi=0^{\circ}\right)$ and at operation frequencies: (a) at $4.3 \mathrm{GHz},(\mathrm{b})$ at $6 \mathrm{GHz},(\mathrm{c})$ at $9 \mathrm{GHz},(\mathrm{d})$ at $18.6 \mathrm{GHz}$.

and data transmissions that were approved by FCC in 2002 [20].

\section{Conclusion}

A method to reduce the size of planar antennas by the integration of $L-C$ elements is demonstrated. The planar transmission line model is applied for the analyses of two different antenna topologies. This model allows preliminary design studies and is able to improve the understanding of structural parametric correlations, for example, the connection between bandwidth and the radiation impedance. As a result, miniature planar antennas with dimensions $12 \times 5.1 \times$ $0.8 \mathrm{~mm}^{3}$ and $18 \times 5.1 \times 0.8 \mathrm{~mm}^{3}$ can be implemented.

Finally two planar patch antennas with overall sizes of $0.17 \lambda_{0}$ by $0.07 \lambda_{0}$ by $0.01 \lambda_{0}$ at $4.3 \mathrm{GHz}$ and $0.25 \lambda_{0}$ by $0.07 \lambda_{0}$ by $0.01 \lambda_{0}$ at $4.3 \mathrm{GHz}$ are realized. These antennas have $122.86 \%$ (from 4.3 to $18 \mathrm{GHz}$ ) and $124.89 \%$ (from 4.3 to $18.6 \mathrm{GHz}$ ) practical bandwidth. Peak gains and maximum radiation efficiencies of the proposed antennas are $7.43 \mathrm{dBi}$ and $84.5 \%$ and $6.03 \mathrm{dBi}$ and $57.57 \%$, which happen at $12 \mathrm{GHz}$ and $16 \mathrm{GHz}$, respectively. Measurements of the realized antennas prove the developed concept and the simulation approach.

\section{Acknowledgments}

The author would like to express his sincere thanks to Research Institute for ICT of Iran (Contract no. 6987/500/T), the Microwave and Millimeter Wave Laboratory of the Amirkabir University of Technology (Tehran Polytechnic) and the antenna laboratory of the K. N. Toosi University of Technology.

\section{References}

[1] H. A. Wheeler, "Fundamental limitations of small antennas," Proceedings of the IRE, vol. 35, no. 12, pp. 1479-1484, 1947.

[2] R. Porath, "Theory of miniaturized shorting-post microstrip antennas," IEEE Transactions on Antennas and Propagation, vol. 48, no. 1, pp. 41-47, 2000.

[3] R. C. Hansen, "Fundamental limitations in antennas," Proceedings of the IEEE, vol. 69, no. 2, pp. 170-182, 1981.

[4] N. Engheta and R. W. Ziolkowski, Eds., Metamaterials: Physics and Engineering Explorations, Wiley-IEEE Press, New York, NY, USA, 2006.

[5] C. Caloz and T. Itoh, Electromagnetic Metamaterials Transmission Line Theory and Microwave Applications, John Wiley \& Sons, New Jersey, 2006.

[6] C. Caloz and T. Itoh, Electromagnetic Metamaterials, Transmission Line Theory and Microwave Applications, Wiley and IEEE Press, New York, NY, USA, 2005.

[7] W. F. Richards and Y. T. Lo, "Theoretical and experimental investigations of a microstrip radiator with multiple lumped linear loads," Electromagnetics, vol. 3, no. 3-4, pp. 371-385, 1983.

[8] G. V. Eleftheriades, A. K. Iyer, and P. C. Kremer, "Planar negative refractive index media using periodically L-C loaded 
transmission lines," IEEE Transactions on Microwave Theory and Techniques, vol. 50, no. 12, pp. 2702-2712, 2002.

[9] C. Caloz and T. Itoh, "Novel microwave devices and structures based on the transmission line approach of meta-materials," in Proceedings of the International Microwave Symposium Digest (IEEE MTT-S '03), pp. 195-198, Philadelphia, Pa, USA, June 2003.

[10] D. Sievenpiper, L. Zhang, R. Broas, N. Alexopulous, and E. Yablonovitch, "High impedance elmomagnetic surfwes with a forbidden frequency hand," IEEE Transactions on Microwave Theory and Techniques, vol. 47, no. 11, pp. 2059-2074, 1999.

[11] Q. Ye, “Time domain response of ultra-wideband dipole antennas," in Proceedings of the International Symposium on Antenna Technology and Applied Electromagnetics (Antem/URSI '04), pp. 661-664, Ottawa, Canada, July 2004.

[12] E. Gazit, "Improved design of the vivaldi antenna," IEEE Transactions on Antennas and Propagation, vol. 135, no. 2, pp. 89-92, 1988.

[13] C. J. Lee, K. M. K. H. Leong, and T. Itoh, "Composite right/lefthanded transmission line based compact resonant antennas for RF module integration," IEEE Transactions on Antennas and Propagation, vol. 54, no. 8, pp. 2283-2291, 2006.

[14] Y. Li, Z. Zhang, J. Zheng, and Z. Feng, "Compact heptaband reconfigurable loop antenna for mobile handset," IEEE Antennas and Wireless Propagation Letters, vol. 10, pp. 1162-1165, 2011.

[15] Y. L. Zhao, Y. C. Jiao, G. Zhao, L. Zhang, Y. Song, and Z. B. Wong, "Compact planar monopole UWB antenna with bandnotched characteristic," Microwave and Optical Technology Letters, vol. 50, no. 10, pp. 2656-2658, 2008.

[16] R. Movahedinia and M. N. Azarmanesh, "A novel planar UWB monopole antenna with variable frequency band-notch function based on etched slot-type ELC on the patch," Microwave and Optical Technology Letters, vol. 52, no. 1, pp. 229-232, 2010.

[17] M. Abdollahvand, G. Dadashzadeh, and D. Mostafa, "Compact dual band-notched printed monopole antenna for UWB application," IEEE Antennas and Wireless Propagation Letters, vol. 9, pp. 1148-1151, 2010.

[18] S. J. Wu, C. H. Kang, K. H. Chen, and J. H. Tarng, "Study of an ultrawideband monopole antenna with a band-notched open-looped resonator," IEEE Transactions on Antennas and Propagation, vol. 58, no. 6, pp. 1890-1897, 2010.

[19] C.-Y. Hong, C.-W. Ling, I.-Y. Tarn, and S.-J. Chung, "Design of a planar ultrawideband antenna with a new band-notch structure," IEEE Transactions on Antennas and Propagation, vol. 55, no. 12, pp. 3391-3397, 2007.

[20] Anon, "FCC First Report and Order on Ultra Wideband Technology," 2002. 

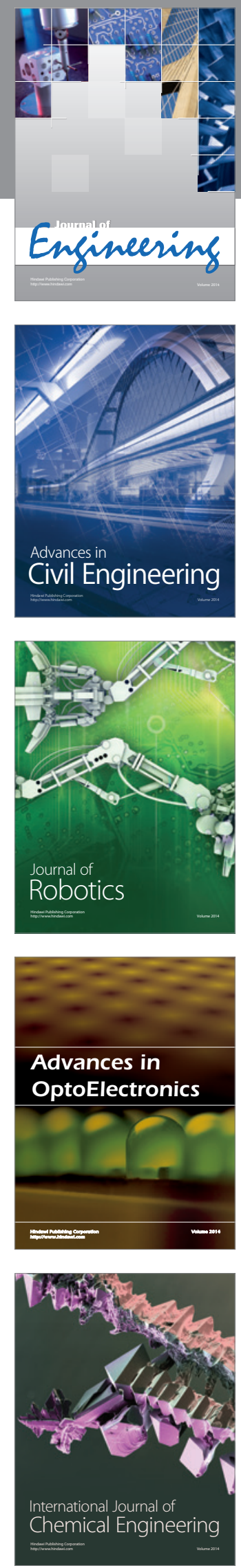

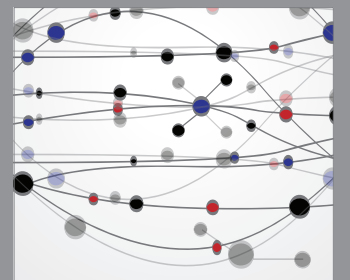

The Scientific World Journal
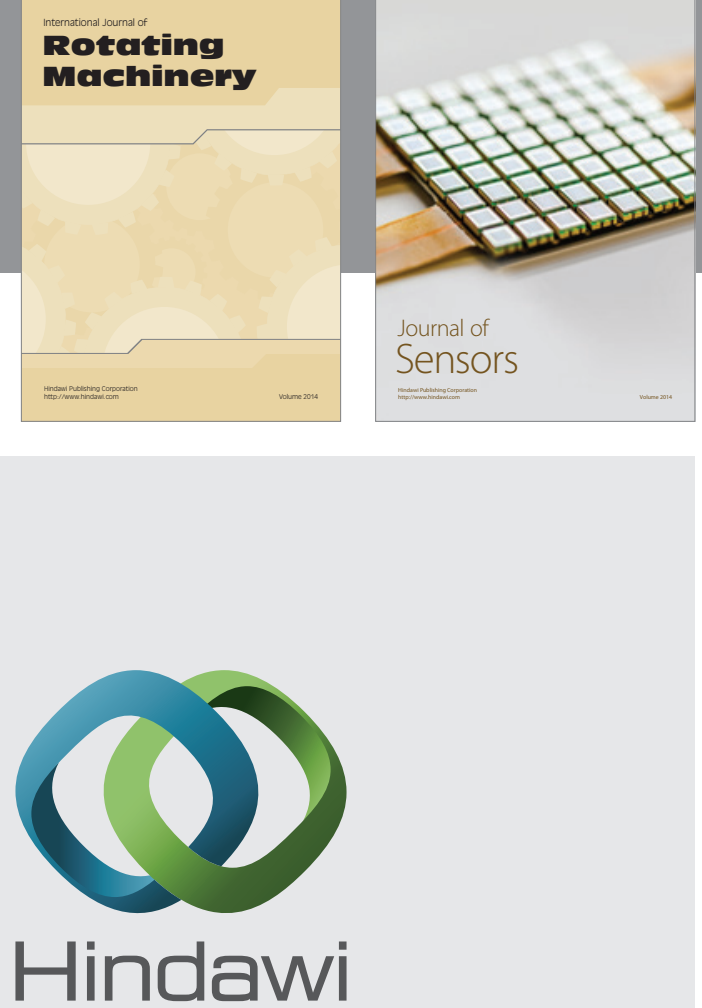

Submit your manuscripts at http://www.hindawi.com
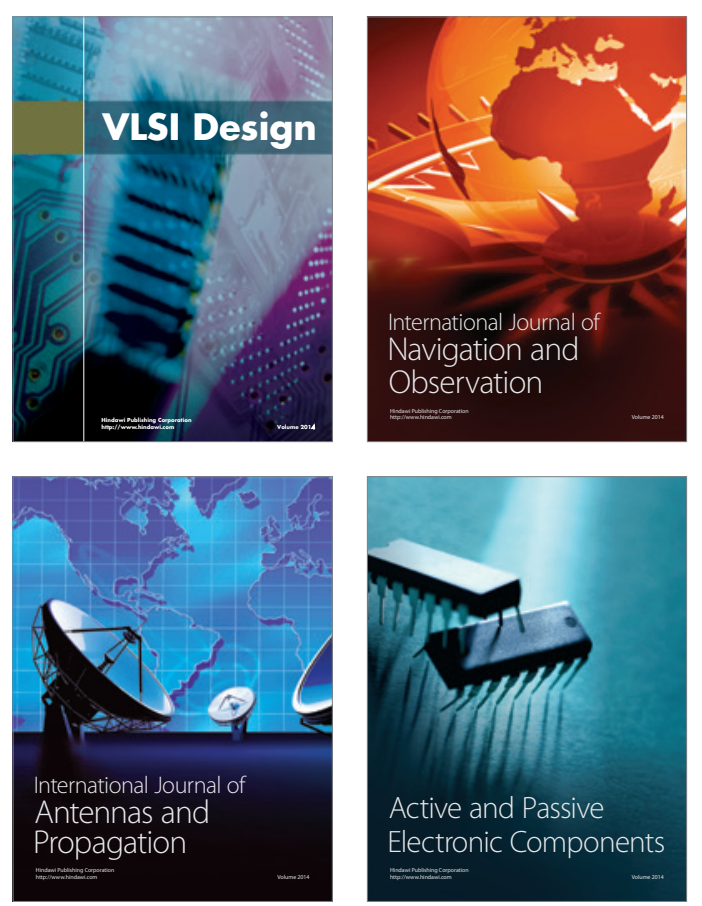
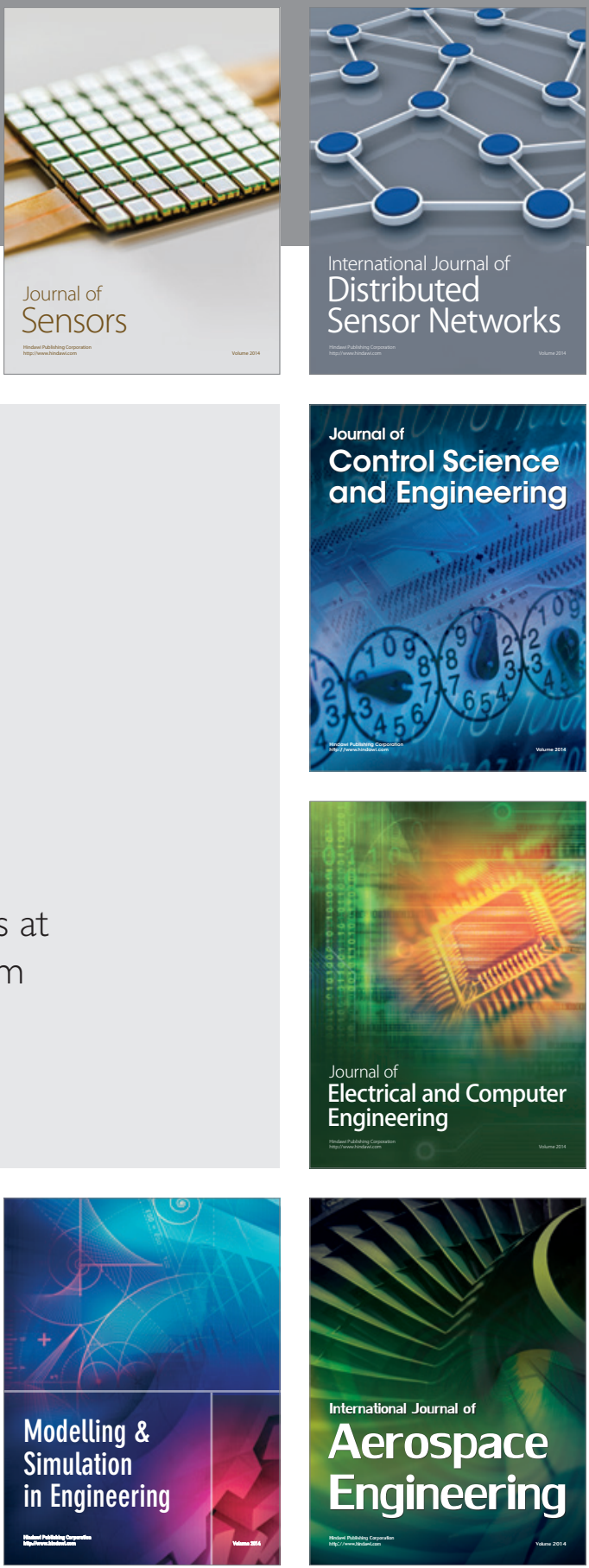

Journal of

Control Science

and Engineering
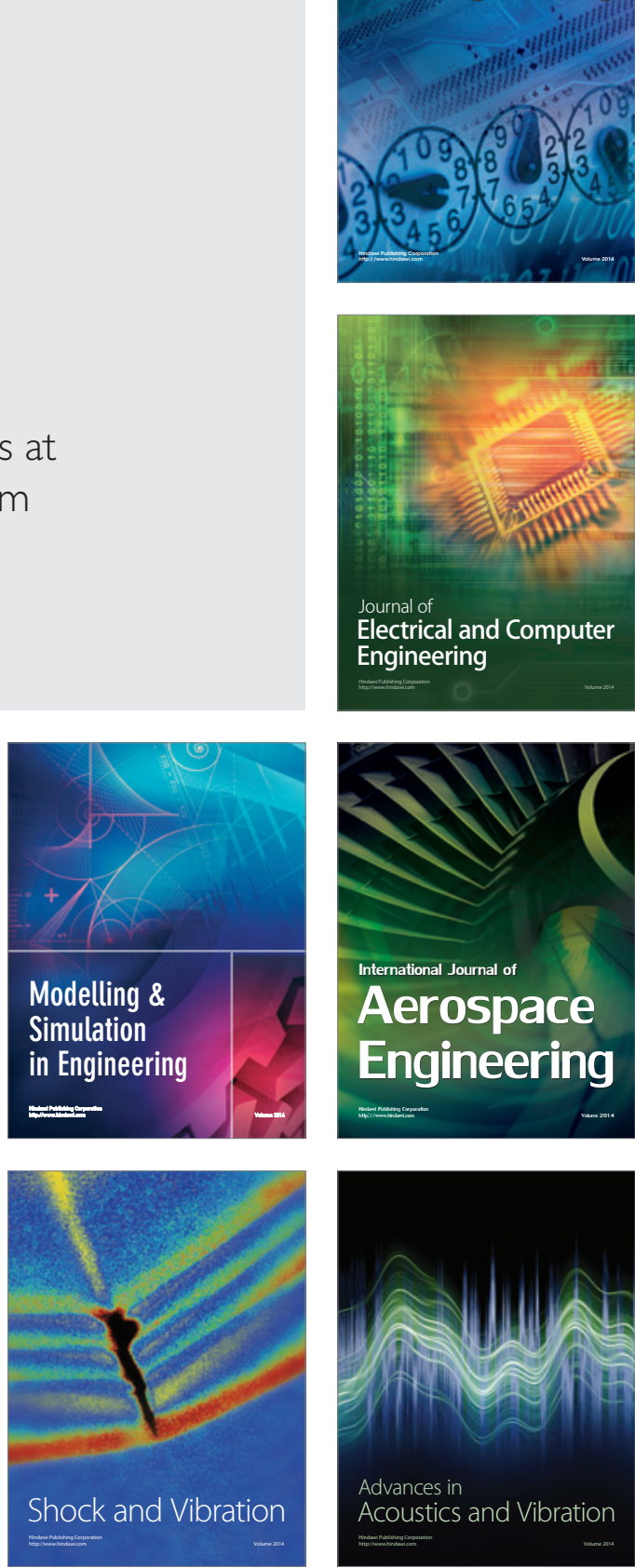